immunology, toxohormone, cell fractionation, histochemistry and enzymology. Vol. 3 is mainly concerned with various aspects of nucleic acid and protein biochemistry, concluding with two chapters on chemotherapy. Both volumes will, I am sure, be of great use to workers in the cancer as well as other fields, but one is forced to think twice about recommending books that cost $272 s$. and 308s., respectively. For volumes of this price one is forced to examine critically where space is not used to full advantage. One major improvement would have been better cross-indexing between chapters which would have produced an appreciable saving of space. This is particularly true in the case of cell fractionation methodology. In addition to the comprehensive reviews given in the specialized chapters in the second volume, a great deal is repeated elsewhere. Thus, Bodansky and Schwartz devote twenty pages of their article in tumour enzymology to methods of cell fractionation. Similarly, it is an expensive luxury to have two complete chapters on nucleoli (vol. 2 and vol. 4 to be published) as well as an appreciable amount of detail in the RNA chapter (vol. 3). The space could have been better used for other articles. One surprising omission is that there is nothing on isotope methodology. Also on the point of indexing, the subject index at the back of the books is very incomplete. Of five topics chosen at random from the text, three were not, in the index.

What is the function of these volumes? In the preface to vol. 2 the editor stresses their use as methodological treatises and, by and large, this has been achieved. In a way, they provide the literary analogue of the research "kits" sold by many commercial firms. Thus the ehapter on "Histochemical and Cytochemical Methods" (vol. 2) is simply a collection of recipes that workers with virtually no knowledge of cytology could follow. As research workers increasingly find the need to cross older frontiers of methodology these volumes will greatly help in this diversification. When delving into a new research area, one of the hardest parts in getting the project off the ground is to decide which method and which modification one should use. This is especially true of the RNA field and the chapter on this topic almost makes it seem easy. Similarly, anyone working with human tumours will, at some stage, encounter the problem of the time gap between removal of the specimen from the patient and the start of experimentation; the discussion by Shonk and Boxer (vol. 2) will greatly help.

Review articles on tumour enzymology are particularly hard to write and to read because the statement that "more people work on cancer than people who have cancer" could be paraphrased to "more people work on tumour enzymes than there are enzymes in tumours". Fortunately, some cohesion is at last coming into this field as illustrated by the article on "Molecular Correlation Concept" (vol. 2). "I was also interested to see that, in considering which enzyme should be studied, the authors of the chapter on the "Enzymology of Solid Human Tumours" (vol. 2) put the relevance to cancer at the top of the list followed by the availability of suitable methodology. All too frequently these priorities are reversed.

In conclusion, they are good books if you can afford them.

R. J. B. KING

\section{NUTRITIONAL BIOCHEMISTRY}

Newer Methods of Nutritional Biochemistry With Application and Interpretations. Vol. 3. Edited by Anthony A. Albanese. Pp. xv +527. (New York: Academic Press, Inc.; London: Academic Press, Inc. (London), Ltd, 1967.) 148s.

IF the word "methods" is taken to imply that this is a practical book, then the title is somewhat misleading; the book deals rather with the findings of the application of new methods of investigation.

This is the third volume of what amounts to a series of monographs dealing in detail with some of the more important topics in the nutrition field. These monographs are particularly useful because they collect together information that is scattered through a wide variety of medical, chemical, biochemical and nutrition journals. Not all are equally useful, as one or two tend to be butterfly surveys of recent publications rather than discussions. For example, one article deals with 422 references in 47 pages. These, however, are the exceptions and the only real criticism that can be levelled against the publication is the discontinuous approach. True, the editor states in the preface that a serious effort was made in the third volume to include areas not previously covered, but this merely underlines the oddity of discussing "In vitro Protein Utilization" in volume 3, "Utilization of Dietary Proteins" in volume 1, "Utilization of Essential Aminoacids by Man" in volume 2, and "Biological Quality of Dietary Proteins" in volume 4 . Nor does it excuse the conglomeration of topies in volume 3 , including zine, folates, lipoproteins, proteins and adrenocorticosteroids.

Apart from this criticism most of the articles themselves are not only useful but excellent, each being written by a. specialist in his own field and intended to bring the reader up to date. For example, the chapter on "Folates in Human Nutrition" (the biochemistry of folic acid was dealt with in volume 2) describes briefly the derivatives and sources as background information and more fully with biochemical function covering the recent work since the larger reviews published in 1963, and then discusses the requirements of human beings at various stages of development and in disease and the effects of folate deficiency. Similarly the chapter on "In vitro Protein Evaluation" covers chemical score and enzymatic and microbiological methods, and then, as the author states that this is his main interest, there follows a valuable discussion of the pepsin digest-residue amino-acid index.

This is an extremely useful book for both nutritionists and biochemists. A. E. BENDER

\section{VITAMINS}

\section{The Vitamins}

Chemistry, Physiology, Pathology, Methods. Vol. 1. Second edition. Edited by W. H. Sebrell, jun., and Robert S. Harris. Pp. xiii +570 . 200s. Vol. 6. Edited by Paul Gyorgy and W. N. Pearson. Pp. xiii +338 . 136s. Vol. 7. Second edition. Edited by Paul Gyorgy and W. N. Pearson. Pp. xiv +354. 163s. 4d. (New York: Academic Press, Inc.; London: Academic Press, Ine. (London), Ltd, 1967.)

During the past decade The Vitamins has been of immense value to many scientists working on various chemical aspects of these fascinating biologically active compounds. The standard of the first volume of the second edition augurs well for the remaining volumes, and one can forecast with some confidence that the new edition will be as sought after as its predecessor. Indeed, the treatise is now made even more comprehensive by the addition of two volumes, now reviewed, on methods of measurement and assay.

Volume $\mathbf{l}$ is concerned with vitamins $\mathrm{A}$ and $\mathrm{C}$; twothirds of the volume cover all aspects of the chemistry, biochemistry, physiology, pathology and pharmacology of vitarnin A; the occurrence, distribution and biosyn. thesis of the vitamin $\mathbf{A}$ active carotenoids are also con. sidered. The remaining two hundred pages deal equally exhaustively with ascorbic acid. 